\title{
Design of a Dual-Band Bidirectional Antenna Using Superellipse-Monopole-Fed Rectangular Ring for IEEE 802.11 a/b/g/n Applications
}

\author{
Ekajit Khoomwong ${ }^{1}$ and Chuwong Phongcharoenpanich ${ }^{2}$ \\ ${ }^{1}$ Faculty of Engineering and Architecture, Rajamangala University of Technology Isan, Nakhon Ratchasima 30000, Thailand \\ ${ }^{2}$ Faculty of Engineering, King Mongkut's Institute of Technology Ladkrabang, Bangkok 10520, Thailand \\ Correspondence should be addressed to Chuwong Phongcharoenpanich; pchuwong@gmail.com
}

Received 11 May 2016; Revised 23 September 2016; Accepted 9 October 2016

Academic Editor: Felipe Cátedra

Copyright (C) 2016 E. Khoomwong and C. Phongcharoenpanich. This is an open access article distributed under the Creative Commons Attribution License, which permits unrestricted use, distribution, and reproduction in any medium, provided the original work is properly cited.

\begin{abstract}
This paper presents the design of a dual-band bidirectional ring antenna fed by a superellipse surface probe for $2.4 / 5 \mathrm{GHz}$ WLAN applications. The Method of Moments (MoM) with RWG basis function was utilized in the study and design processes. A prototype antenna was fabricated successfully with the advantages of simple and low-cost structure. The measured impedance bandwidth of $810 \mathrm{MHz}(2.10-2.91 \mathrm{GHz})$ and $2.39 \mathrm{GHz}(3.57-5.96 \mathrm{GHz})$ is achieved for the first and second band, respectively. The peak gains are also feasible, $4.67 \mathrm{dBi}$ at $2.45 \mathrm{GHz}$ and $7.83 \mathrm{dBi}$ at $5.5 \mathrm{GHz}$, with bidirectional radiation patterns for both bands. From the experimental field tests, the proposed antenna was suitable for most applications in long and narrow communication sites in $2.4 / 5 \mathrm{GHz}$ bands as desired. Also, the measured and calculated results were in good agreement.
\end{abstract}

\section{Introduction}

Wireless local area networks (WLAN) recently received widespread attention due to their convenience and costeffectiveness in many circumstances compared to conventional wired networks. However, in response to the demands of different frequency standards of WLAN, for example, IEEE $802.11 \mathrm{~b} / \mathrm{g}(2.4-2.484 \mathrm{GHz})$ and IEEE 802.11a (5.15$5.35 / 5.725-5.825 \mathrm{GHz}$ ), modern antennas being used in these systems should have multiband features. So far, various elements and techniques have been proposed and implemented on antennas to yield multiband characteristics for WLAN and other wireless communication applications, such as multiradiators or radiating elements [1-3]. Typically, other techniques such as resonant slits, slots, or stub structures [411] are also attractive for designing multiband antennas.

To serve the demands for long and narrow communication paths, such as streets, tunnels, and subway stations, bidirectional antennas are likely to be the most promising candidates. There are many research topics on bidirectional antennas such as [12-16] that extensively used various ring shapes (i.e., waveguide sections with moderate widths) such as rectangular, circular, and elliptical rings, to force the radiating beams in two opposite directions. Some other techniques are also introduced such as collinear antennas with parasitic wire elements in $[17,18]$ and a fractal patch antenna with pattern reconfigurable capability in [19].

The Method of Moments (MoM) is a frequency-domain technique, which is very useful and usually utilized in computational electromagnetics such as scattering and radiating problems. The process of calculations and its solutions are widely known and improved for many decades, and its evolution was recently overviewed in [20].

Generally, there are some drawbacks of using MoM in designing antennas such as limitations in application to radiation or scattering calculations from large structures due to computational resources that scaled with square of unknowns and also a convergence problem of solutions with complex structures, specifically ones that are comprised of various part sizes in the same area. However, there are main advantages of the MoM such as efficient computational resource usage for problems with small surface areas compared to the total 


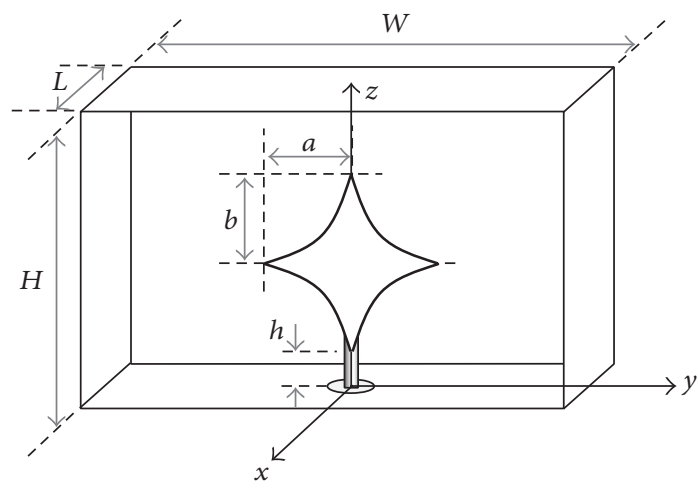

Figure 1: An antenna structure and its parameters.

volume (e.g., problems with only thin conducting surfaces and free space) and with low complexity in calculation process.

Furthermore, many basis functions and computational techniques of MoM have been considered for applying to electromagnetic scattering and radiating problems such as [21-29]. Among these, Rao-Wilton-Glisson (RWG) [21] basis function was still acceptable as one of the most popular basis functions used in antenna analyses and designs. Here, we consider utilizing of the MoM with RWG basis function in the antenna design because it is uncomplicated in the calculation process and suitable for creating a low-cost custom software package. It can be conveniently tailored for this specific structure of antenna with superellipse shapes and can also expedite the automatic parameter sweeping process with moderate accuracy. Although there are many high-end commercial software packages available nowadays, they usually come with high prices. Furthermore, some issues are found in their operations that cannot be solved by users themselves. For instance, in some software packages, one of most common problems is that they do not support inputting of a non-one-to-one analytical function directly (e.g., a superellipse curve family) due to complexity in automatic mesh-generation process and thus impede or sometimes obstruct the parameter sweeping and designing processes.

In this paper, we provide the details of analyses, comparisons, operational mechanism explanations, and discussions of a rectangular ring antenna proposed in [30], which is excited by a superellipse surface probe to provide dualband characteristic for $2.4-2.484 \mathrm{GHz}$ and 5.15-5.35/5.725$5.825 \mathrm{GHz}$ WLAN applications with bidirectional radiation patterns enforced by the ring. The superellipse or Lamé curve is a key function employed to investigate and achieve dualand wideband attribute. The study and design of the antenna are mainly performed by utilizing the Method of Moments with the Rao-Wilton-Glisson basis function (MoM-RWG) [21].

\section{Antenna Structure and Parameters}

An antenna structure and its parameters are illustrated in Figure 1 where $a$ and $b$ are semiaxis lengths of the superellipse surface probe along the $y$ - and $z$-direction, respectively. The

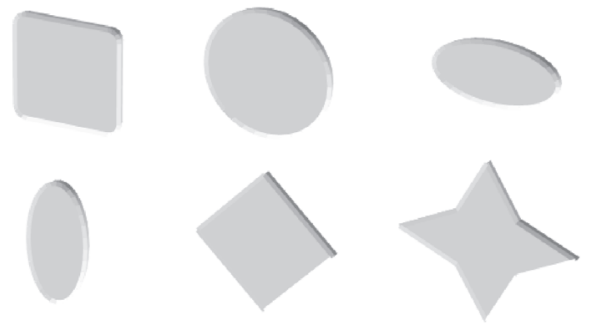

Figure 2: Typical basic shapes of the surface probe.

surface probe is attached at the tip of a thin feeding probe with height, $h$. The rectangular ring surrounding the probe has width, height, and length of $W, H$, and $L$, respectively.

As mentioned above, the superellipse or Lamé curve is a key function to be used for generating different shapes of the surface probe, so its geometrical function should be stated clearly with related parameters on the $y-z$ plane, as in

$$
\left(\frac{y}{a}\right)^{v}+\left(\frac{z}{b}\right)^{v}=1
$$

The parameter $v$ is a nonzero positive value, sometimes called a squareness parameter since it tends to make the curve nearly square while its value is approaching infinity. It is possible that (1) can be solved into explicit parametric form of coordinates $(y, z)$ as in (2); then some basic shapes of the surface probe can be generated by using (2), which are typically depicted in Figure 2:

$$
\begin{aligned}
& y=a \cdot \psi(\beta) \cos (\beta), \\
& z=b \cdot \psi(\beta) \sin (\beta),
\end{aligned}
$$

where $\psi(\beta)=\left(|\sin (\beta)|^{\nu}+|\cos (\beta)|^{\nu}\right)^{-1 / \nu}$ and $\beta$ is an angle ranging from 0 to $2 \pi$ for a full circumference.

\section{Antenna Design and Simulation}

3.1. Formulation of the Method of Moments. As previously stated, the Method of Moments with RWG basis function is utilized in the study and design processes of the antenna. By considering the electric field integral equation (EFIE) under open boundary condition, we may approximate the surface current density on antenna's metallic body in terms of RWG basis function, as in

$$
\bar{J} \cong \sum_{n=1}^{N} \bar{I}_{n} \bar{f}_{n}(\bar{r}),
$$

where $\bar{J}$ is the surface current density, $\bar{f}_{n}$ is the RWG basis function, and $\bar{I}_{n}$ is an expansion coefficient of current density. When the antenna structure is discretized by triangulation and incorporating with (3), the EFIE can be approximated and solved for $\bar{I}_{n}$ in form of matrix equation as

$$
\left[Z_{m n}\right]\left[\bar{I}_{n}\right]=\left[\bar{V}_{m}\right]
$$




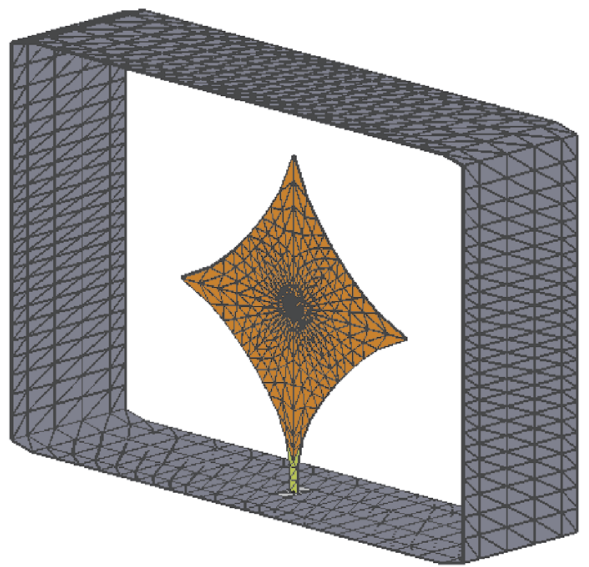

Figure 3: An example of triangulated antenna structure.

where $\left[Z_{m n}\right]$ is an impedance matrix of size $M \times N$. $\left[\bar{I}_{n}\right]$ and $\left[\bar{V}_{m}\right]$ are the expansion coefficient vector and the applied voltage source vector, respectively. More detailed formulations and other parameter descriptions can be found in [21].

\subsection{Triangulation of the Antenna Structure. As insisted ear-} lier, the calculation domain is required to be discretized by triangulation to implement the Method of Moments with RWG basis function. Roughly, there are two categories of triangulation process, nonuniform and uniform type. For instance, the Delaunay triangulation is the nonuniform type dealing with some random functions and optimization techniques thus may require extensive computation resources, but it can be applied to any shapes of structures. On the other hand, the uniform type triangulation is much simpler and straight forward requiring only predefined parametric formulas of coordinates, but it may handle only simple geometric structures. Since in this paper the antenna is comprised of simple structures such as a rectangular ring and a superellipse surface probe, it is convenient to employ the uniform-type triangulation. For the superellipse surface probe, (2) can be rewritten in discretized form as

$$
\begin{aligned}
& y_{i}=a_{k} \cdot \psi\left(\beta_{i}\right) \cos \beta_{i}, \\
& z_{i}=b_{k} \cdot \psi\left(\beta_{i}\right) \sin \beta_{i},
\end{aligned}
$$

where $\beta_{i}$ is a discretized angle along the circumference of the shape. Thus $\beta_{i}=i \Delta \beta$, where $i=0,1,2, \ldots, N_{\beta}$ and $\Delta \beta=2 \pi / N_{\beta}$. In the radial direction, step layers are defined by $a_{k}=k \Delta a$ and $b_{k}=k \Delta b$, where $k=0,1,2, \ldots, N_{r}$, $\Delta a=a / N_{r}$, and $\Delta b=b / N_{r}$. For the rectangular ring, the similar approach of triangulation can be applied. As a general example, a triangulated antenna structure with $a=b=$ $1.5 \mathrm{~cm}, v=0.75 \mathrm{~cm}, W=3 \mathrm{~cm}, H=2 \mathrm{~cm}, L=1.5 \mathrm{~cm}, h_{f}=$ $0.3 \mathrm{~cm}, N_{\beta}=32$, and $N_{r}=6$ is shown in Figure 3 .

3.3. Design and Simulation Processes. In order to design the antenna, it is important to know initial antenna parameters to be used. Then the parametric study can be performed to evaluate the optimal or suitable sets of antenna parameters.
Most of initial parametric values are selected based on classical analytic formulas.

For the ring element of the antenna, the design formula for a rectangular waveguide is utilized to obtain the dimensions, $W$ and $H$, as follows:

$$
\begin{aligned}
& W=\frac{3 \times 10^{8}}{\left(2 f_{c}\right)}, \\
& H \leq K_{H} \times \frac{W}{2},
\end{aligned}
$$

where $f_{c}$ is the cutoff frequency of a rectangular waveguide.

The coefficient $K_{H}$ is a constant factor, typically in the range from 0.5 to 1.5 , which increases the waveguide's height from the optimal bandwidth case to accommodate a large surface probe. For the surface probe, due to a variety of parameters affecting the resonant length, a simple rule of electrical length is adapted, which is relating to the feeding probe parameters as

$$
a+2 b+h \cong \frac{\lambda}{4}
$$

where $\lambda$ is the wavelength of a desired operating frequency.

From (6) and (7), we use the center operating frequency of the first band, that is, $2.45 \mathrm{GHz}$; thus the initial parameters are predicted as follows: $W=72 \mathrm{~mm}, H=72 \mathrm{~mm}, L=22 \mathrm{~mm}$, $a=11 \mathrm{~mm}, b=11 \mathrm{~mm}$, and $h=1.75 \mathrm{~mm}$. Please note that all parameters above are only approximate dimensions, not accounting for the coupling effect of antenna elements. The suitable parameters are to be evaluated by parametric study.

In addition to the simulation process, the triangulation related parameters of the antenna structure, such as $N_{\beta}$ and $N_{r}$, are estimated by a convergence criterion as the shortest edge element's length $\left(l_{n}\right)$, defined in [21], should be $<\lambda / 5$ of the highest frequency. The criterion is specifically based on the MoM simulations of the proposed antenna, and the graphical results and discussions are omitted here for the sake of brevity.

3.4. Parametric Study and Design Results. The parametric study is performed by first varying the parameter $\nu$ to investigate the effect of superellipse probe shapes on the impedance characteristic of the antenna, while other parameter values are fixed as mentioned above.

Figure 4 depicts results of impedance characteristics for typical values of $\nu$ at two frequencies, $f_{1}=2.5 \mathrm{GHz}$ and $f_{2}$ $=5.5 \mathrm{GHz}$, near the centers of both operating bands. It is observed that the star-shaped probes $(v<1$, see Figure 5 for shapes) exhibit high resistances, especially at the higher band $\left(f_{2}\right)$. For the reactance characteristics, the highly fluctuating values, that is, from capacitive to inductive, can be obviously observed at $f_{2}$, whereas the low disturbance ones can be seen at $f_{1}$ in capacitive region. When $v \geq 1$, the impedance characteristics start to converge to some reasonable points. Specifically, for $v \geq 10$, stable impedances can be observed.

Figure 5 summarizes the results of impedance bandwidth characteristics for typical values of $v$ along with some images of probe shapes. It is observed that, for the frequency range 


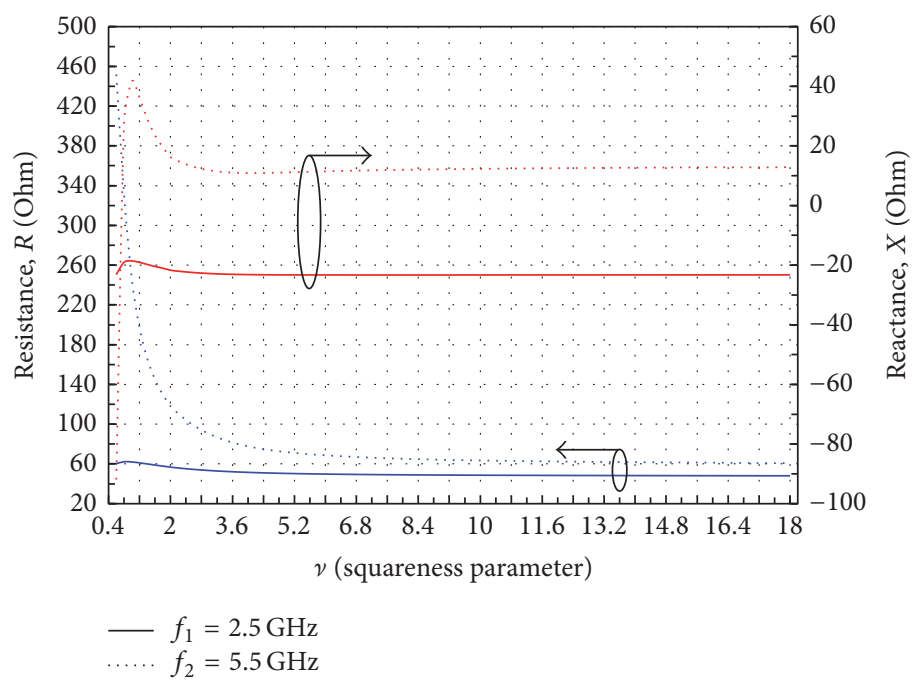

FIGURE 4: Impedance characteristics versus typical values of $\nu$.

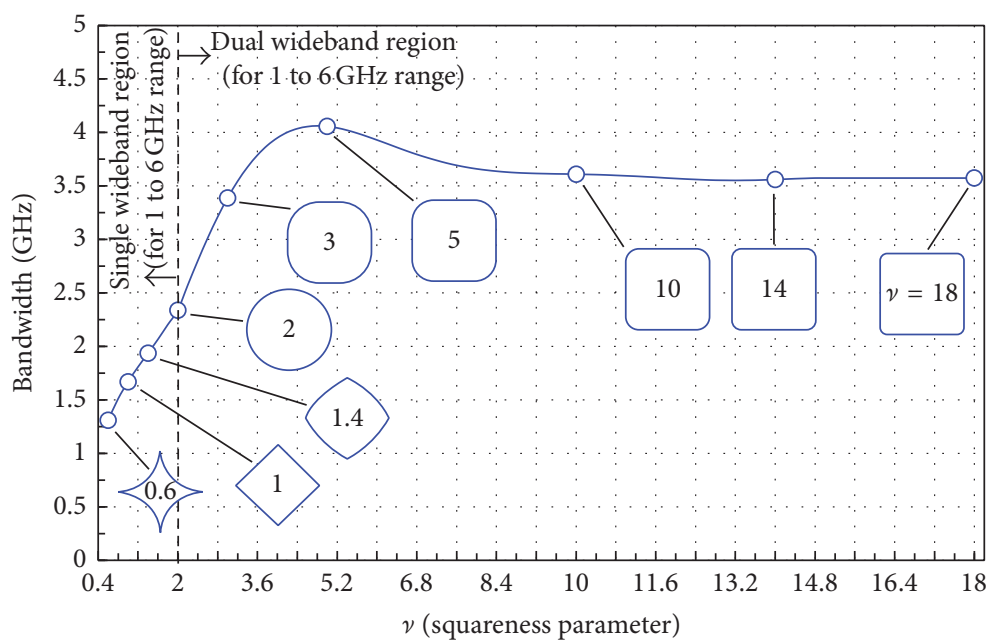

FIGURE 5: Bandwidth characteristics versus typical values of $\nu$.

of 1 to $6 \mathrm{GHz}$, a star-shaped probe possesses single-band property since it tends to increase the resistance when $v$ is decreased, and it has more significant effects on the second operating band. Thus the star-shaped probe is more suitable for single narrow- or single wideband applications in this specific configuration. When $v \geq 1.0$, broader impedance bandwidths can be achieved because of lower resistance and more inductive loading effect of the surface probe diminishing the capacitive reactance characteristic of the antenna. Finally, it is obviously remarked that to obtain a dual-band characteristic, the value of $v$ greater than 2 should be applied. From now on, $v=18$ is used since it has stable impedance characteristic near the $2.4 / 5-\mathrm{GHz}$ bands as required and yields a good compromising point and also has an advantage of simple shape for ease of fabrication process with lower shaping tolerance.

Figures 6 and 7 illustrate the effects of main parameters, that is, $a, b, W, H$, and $L$, on the magnitude of $S_{11}\left(\left|S_{11}\right|\right)$ curves at $-10 \mathrm{~dB}$ level. In the simulations, while one parameter is varying other ones are fixed at their initial parametric values.

Figures 6(a) and 6(b) show $\left|S_{11}\right|$ characteristics by varying sizes of the surface probe, $a$ and $b$. In Figure 6(a), the dualband characteristic is obtained at $a=9$ and $11 \mathrm{~mm}$ particularly for the $2.4-\mathrm{GHz}$ band and nearly achieved for the $5-\mathrm{GHz}$ band.

Also, in Figure 6(b), it is observable that good dual-band characteristic is obtainable near $b=13$ and $15 \mathrm{~mm}$. When both of the parameters are considered at the same time it is found that the suitable values of $a$ and $b$ are $9 \mathrm{~mm}$ and $14 \mathrm{~mm}$, respectively, and to be set as new initial parametric values.

Figures $7(\mathrm{a})-7(\mathrm{c})$ depict $\left|S_{11}\right|$ by varying dimensions of the ring, $W, H$, and $L$. In Figure $7(\mathrm{a}), W$ affects the matching frequency and bandwidth, more significantly for the higher band. At this stage, a good compromising point is $W=$ $64 \mathrm{~mm}$. 


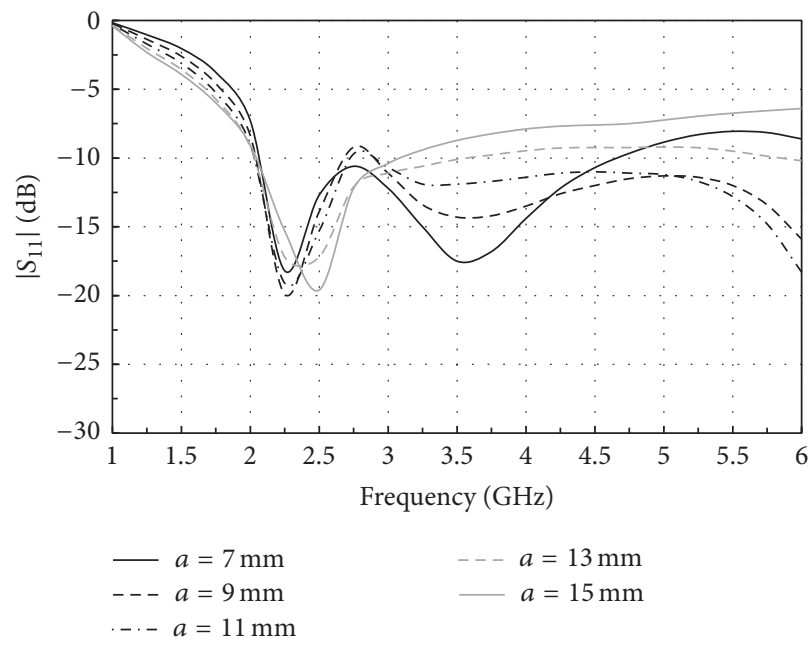

(a)

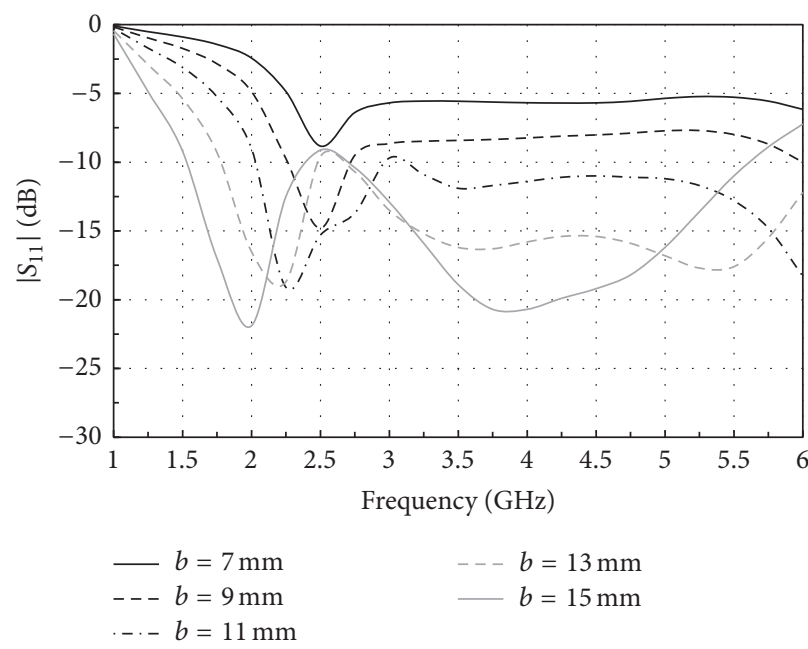

(b)

FIgURE 6: (a) Characteristics of $\left|S_{11}\right|$ by varying $a$. (b) Characteristics of $\left|S_{11}\right|$ by varying $b$.

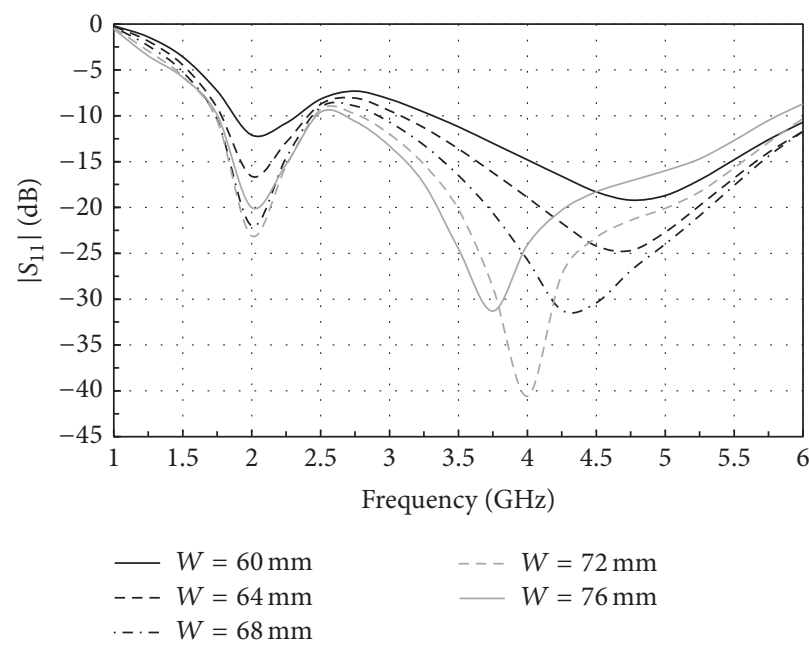

(a)
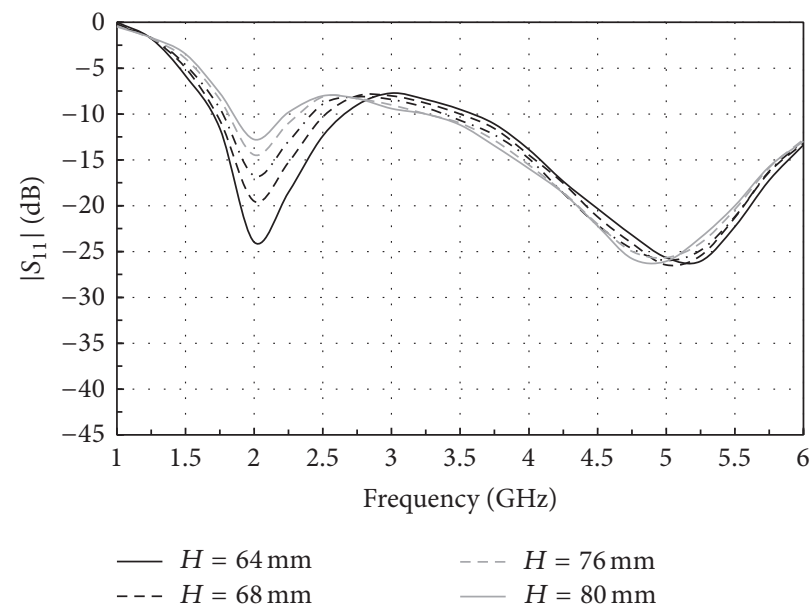

-. - $H=72 \mathrm{~mm}$

(b)

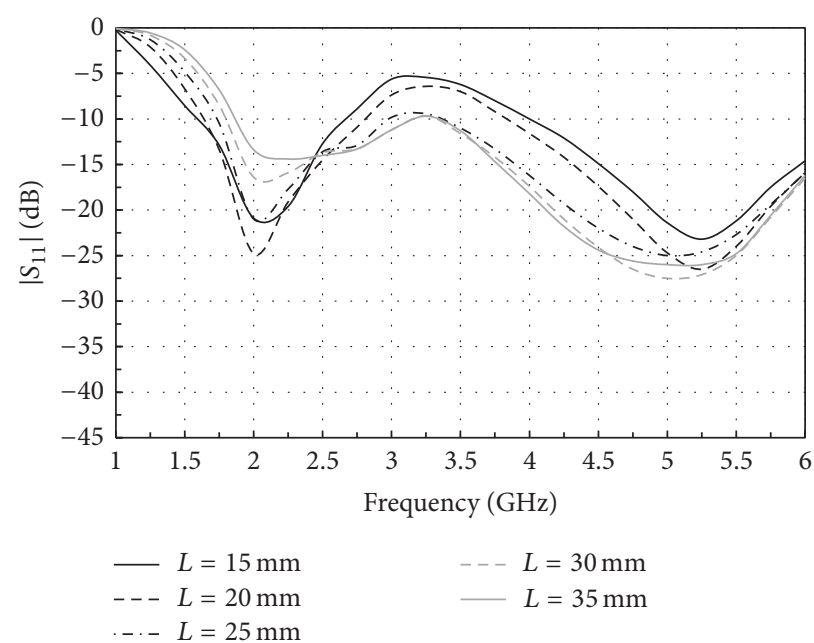

(c)

Figure 7: (a) Characteristics of $\left|S_{11}\right|$ by varying $W$. (b) Characteristics of $\left|S_{11}\right|$ by varying $H$. (c) Characteristics of $\left|S_{11}\right|$ by varying $L$. 


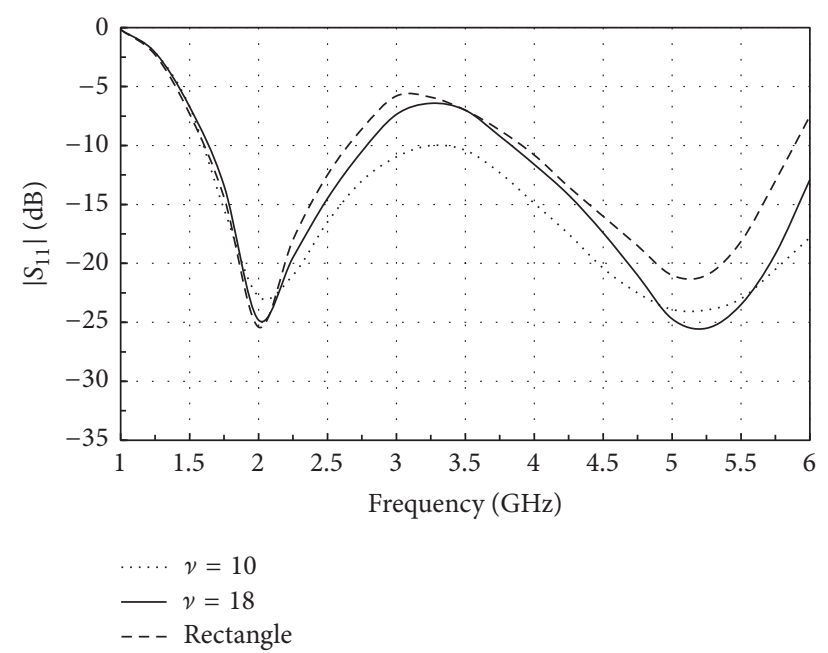

FIGURE 8: Characteristics of $\left|S_{11}\right|$ by varying $\nu$.

Then, $W=64 \mathrm{~mm}$ is used as a new fixed parametric value, leading to the results as in Figure 7(b). Obviously, when $H$ is higher the matching is more degraded for the first band, and the operating frequency is slightly lower for the second band. For Figure 7(c), the matching of the first band is affected significantly by varying $L$ of the ring. It is obvious that a new parametric value is better near $L=20 \mathrm{~mm}$.

At this point, to verify that the selected value of $\nu=18 \mathrm{can}$ still provide a good compromise between the characteristic of being dual-band and the impedance matching near the higher band as depicted in Figure 8 by varying typical values of $v$. It is noticeable that, at $v=10$, the dual-band characteristic is degraded as it tends to be excessively wide for the specific bandwidth requirement of this paper. Meanwhile, as $\nu \rightarrow \infty$ (i.e., a perfect rectangular probe), the impedance matching characteristic is worsened near the higher frequency range since the sharp corners of the rectangular surface probe affect the current flow at the probe edges more than the round and smooth ones, which often seen in applications of microwave circuits as beveled or round edge transitions. Therefore the selected round rectangle shape $(\nu=18)$ can noticeably improve the impedance matching near the higher band.

In addition to the parametric study above, the impedance matching can be further adjusted by fine tuning the parameter $h$, that is, height of the feeding tip. After iterating in some more parametric study processes, it is found that the optimal set of parameters can be obtained as in Table 1 and the final triangulated antenna model is illustrated in Figure 9. It should be noted that the rectangular ring model has small bevels at its corners to equivalently account for roundness of the folded copper strip to form the ring, that is, following the plan in the fabrication process.

3.5. Operation Mechanism. To further investigate the main working principle of the proposed antenna, more parametric study and surface current density are considered. The final model and parametric values obtained from Section 3.4 are used to illustrate its mechanism of operation.

First, to proceed with more parametric study process we consider an exchange of the superellipse surface probe with
TABLE 1: Optimal set of parameters.

\begin{tabular}{lc}
\hline Parameter & Value \\
\hline$a$ & $9.1 \mathrm{~mm}$ \\
$b$ & $14.0 \mathrm{~mm}$ \\
$v$ & 18 \\
$h$ & $1.7 \mathrm{~mm}$ \\
$W$ & $66 \mathrm{~mm}$ \\
$H$ & $67 \mathrm{~mm}$ \\
$L$ & $23 \mathrm{~mm}$ \\
\hline
\end{tabular}

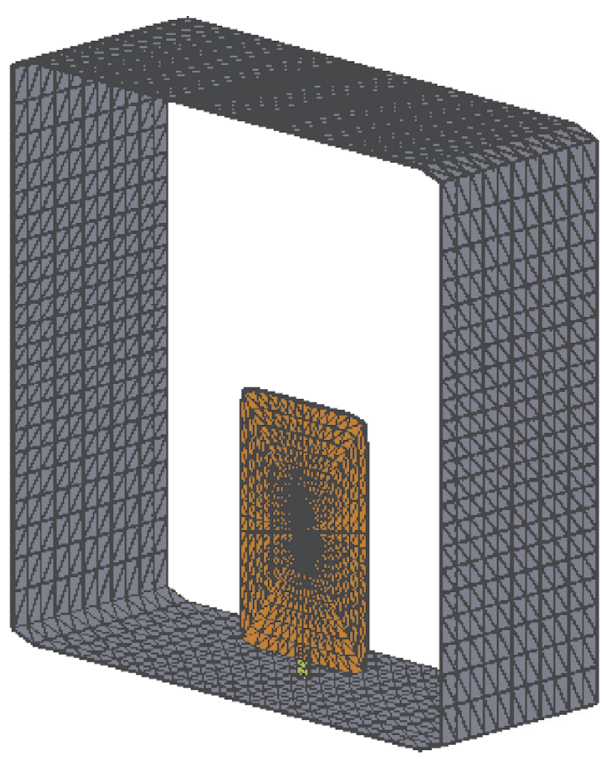

FIGURE 9: The final triangulated antenna structure.

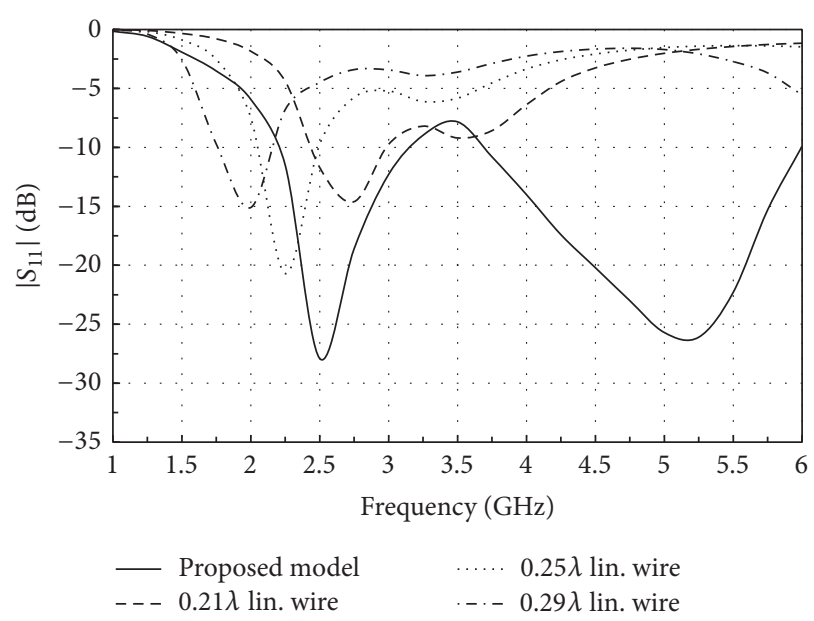

Figure 10: $\left|S_{11}\right|$ of linear-wire probe versus the proposed model.

a simple linear-wire probe having a resonant length of about quarter wavelength $(\lambda / 4)$ of the first operating frequency $f_{1}$, which is related to the original feeding models proposed in $[12,13]$ and more recent literatures in [14-16]. The parametric study results of $\left|S_{11}\right|$ of the final rectangular ring with the exchanged linear-wire probe are shown in Figure 10, along with $\left|S_{11}\right|$ from the proposed final model from Figure 9. It 


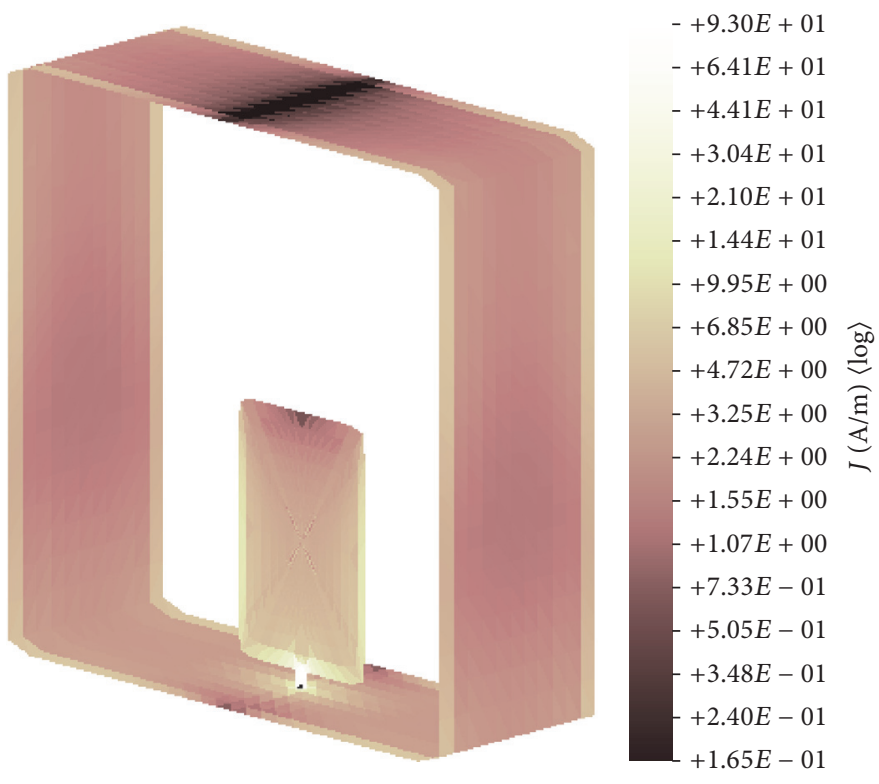

Freq. $2.45 \mathrm{GHz}$

FIGURE 11: Current density on the proposed model at $2.45 \mathrm{GHz}$.
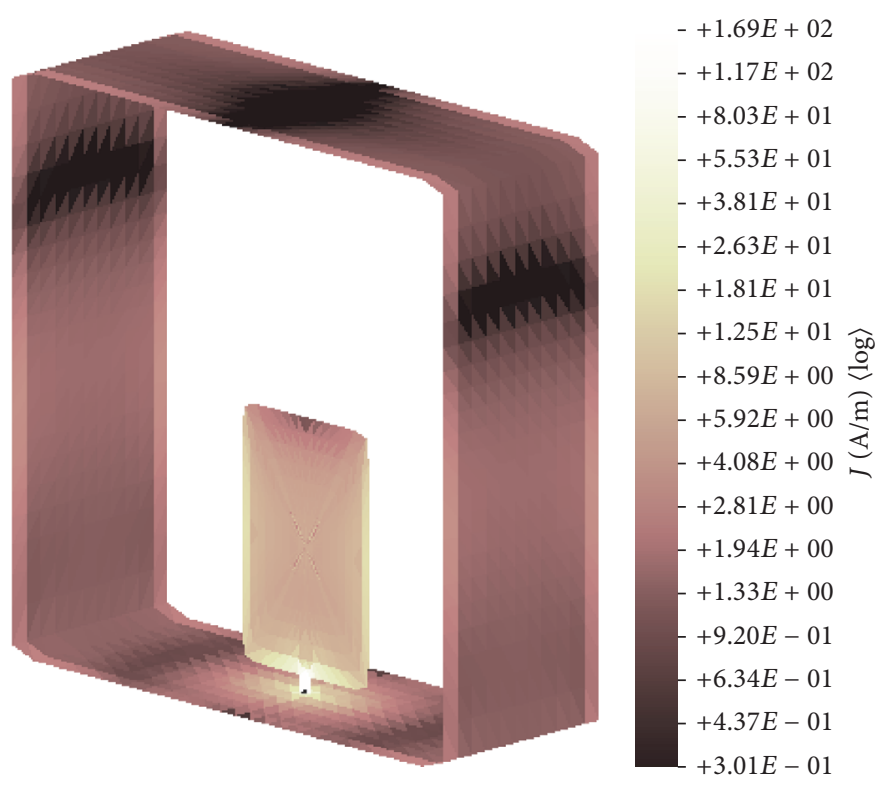

Freq. $5.5 \mathrm{GHz}$

FIGURE 12: Current density on the proposed model at $5.5 \mathrm{GHz}$.

is apparent that excitation by the linear-wire cannot generate the higher mode (i.e., higher frequency) of operation for this antenna configuration in the frequency range from 1 to $6 \mathrm{GHz}$. Thus the linear-wire probe mainly supports only single band of operation in this case when compared with the final proposed structure.

Second, to further explain the dual-band characteristic of the proposed antenna the surface current densities on its body are examined as shown in Figures 11 and 12 for the first $\left(f_{1}\right)$ and second $\left(f_{2}\right)$ frequency of $2.45 \mathrm{GHz}$ and $5.5 \mathrm{GHz}$, respectively. As depicted in Figure 11, the current density at $f_{1}=2.45 \mathrm{GHz}$ reflects the fundamental mode of operation with one set of current maximum and minimum point on the rectangular ring and also on the feeding surface probe itself. In Figure 12, the current density at $f_{2}=5.5 \mathrm{GHz}$ reveals that the higher mode of resonant operating frequency occurs, obviously with two sets of current maxima and minima on the rectangular ring and also with noticeable different patterns of current near the surface probe by comparing with that of the first frequency. 


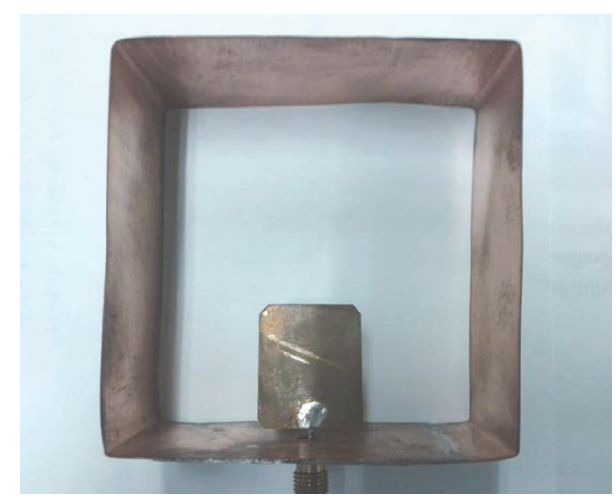

FIgURE 13: Photograph of a prototype antenna.

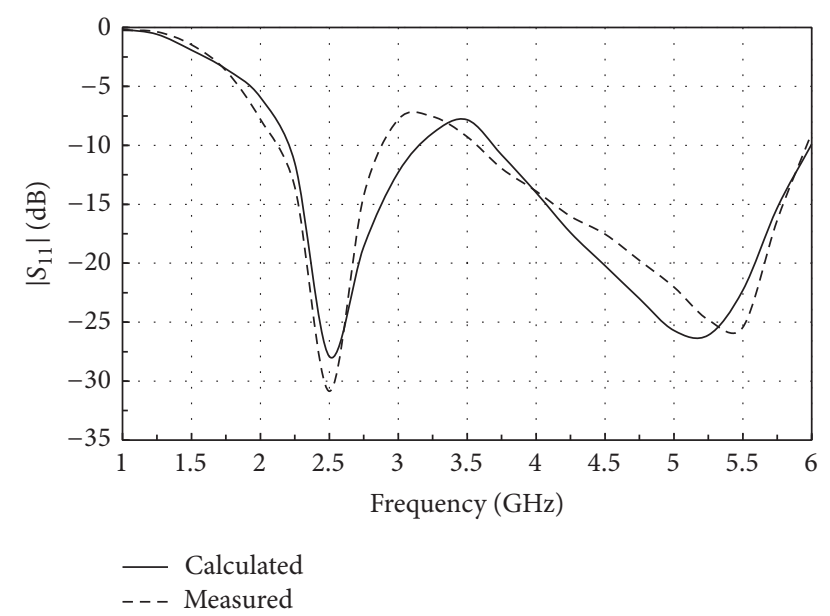

Figure 14: Calculated and measured results of $\left|S_{11}\right|$.

\section{Measurement Results and Discussions}

To validate the design of the MoM-RWG, a prototype antenna was fabricated with the optimal set of parameters from the preceding section, as shown in Figure 13. The rectangular ring and superellipse surface probe were created by directly cutting from a thin copper sheet, which were found low-cost and practical for arbitrary sizes of the ring and various shapes of the surface probe.

In Figure 14, the measured results of $\left|S_{11}\right|$ are compared with ones from the calculations. The results are found in good agreement except the slight shift near the second band. The discrepancies may arise from the SMA and probe feeding.

From Figure 14, the measured impedance bandwidth $\left(\left|S_{11}\right| \leq-10 \mathrm{~dB}\right)$ of the first band is $810 \mathrm{MHz}(2.10-2.91 \mathrm{GHz})$ with $\left|S_{11}\right|$ matching $-27.39 \mathrm{~dB}$ at the center frequency, $2.45 \mathrm{GHz}$. For the second band, the measured impedance bandwidth is $2.39 \mathrm{GHz}(3.57-5.96 \mathrm{GHz})$ with the $\left|S_{11}\right|$ matching $-25.44 \mathrm{~dB}$ at the center frequency, $5.5 \mathrm{GHz}$.

Finally, the results of far-field characteristics such as radiation patterns and gains are compared between the calculation and measurement. The radiation patterns are compared as shown in Figures 15 and 16 to confirm the
TABLE 2: Comparison of peak gain and antenna efficiency.

\begin{tabular}{lcccc}
\hline \multirow{2}{*}{ Frequency $(\mathrm{GHz})$} & \multicolumn{2}{c}{ Peak Gain $(\mathrm{dBi})$} & \multicolumn{2}{c}{ Efficiency $\left(\eta_{\text {total }}\right)$} \\
& Calculated & Measured & Calculated & Measured \\
\hline 2.4 & 4.64 & 4.52 & 0.992 & 0.894 \\
2.45 & 4.86 & 4.67 & 0.996 & 0.885 \\
2.5 & 4.97 & 4.73 & 0.998 & 0.879 \\
5.2 & 7.11 & 7.10 & 0.997 & 0.921 \\
5.5 & 7.92 & 7.83 & 0.994 & 0.909 \\
5.8 & 7.98 & 7.85 & 0.962 & 0.875 \\
\hline
\end{tabular}

bidirectional property of the antenna. Figure 15 shows normalized radiation patterns in the E-plane at the frequencies of 2.45 and $5.5 \mathrm{GHz}$. It is noticeable that the main beam directions are pointing to almost the same angle of 75 degrees.

Figure 16 shows normalized radiation patterns in the $\mathrm{H}$ plane with the two main beams directing along the ring's apertures. From Figures 15 and 16, it is evident that the proposed antenna has bidirectional property as desired. Since the radiation patterns have slightly tilt-angle characteristics with upward angle about 15 degrees, the proposed antenna is most suitable for the ceiling-mounted or wall-mounted installation.

To compare the peak gains and total efficiencies $\left(\eta_{\text {total }}\right)$ of the antenna from the calculation and measurement, some frequencies in both operating bands were selected and measured as shown in Table 2. Please note that all the calculated gains and efficiencies are accounting only for the reflection efficiency since all conductor parts are assumed PEC. From the results, the calculated and measured peak gains are agreed fairly well. However, there are some discrepancies due to the PEC structure assumed in the calculations and also arise from some tolerances in the fabrication process.

Finally, Table 3 shows the comparison of typical measured characteristics of the proposed antenna versus some other models that have bidirectional radiation patterns for specific purpose in the $2.4 \mathrm{GHz}$ and/or $5 \mathrm{GHz}$ WLAN bands. The first two models, \#1 and \#2, are for the single-band operation at $2.4 \mathrm{GHz}$ with the features of dual polarization. It is noticeable that the structure in [31] has the lowest gain due to the circularly polarized radiation. For the dual-band characteristics, $\# 3$ to $\#$, the model in $[33,34]$ has similar configurations with some modifications of radiating elements. They provide high average gains of both bands. However, both of them are not covering the lower range of the $5-\mathrm{GHz}$ band and having larger antenna size because of the ground planes. From the comparison above, it is obvious that the proposed antenna has the main advantage of covering the entire $2.4 \mathrm{GHz}$ and $5 \mathrm{GHz}$ bands with sufficient gains and moderate size.

\section{Conclusions}

In this paper, we have presented the design of a dual-band bidirectional ring antenna that is excited by a superellipse surface probe for applications in 2.4 and $5 \mathrm{GHz}$ WLAN bands. In the design processes, the Method of Moments (MoM) with RWG basis function was adopted. A prototype antenna was 


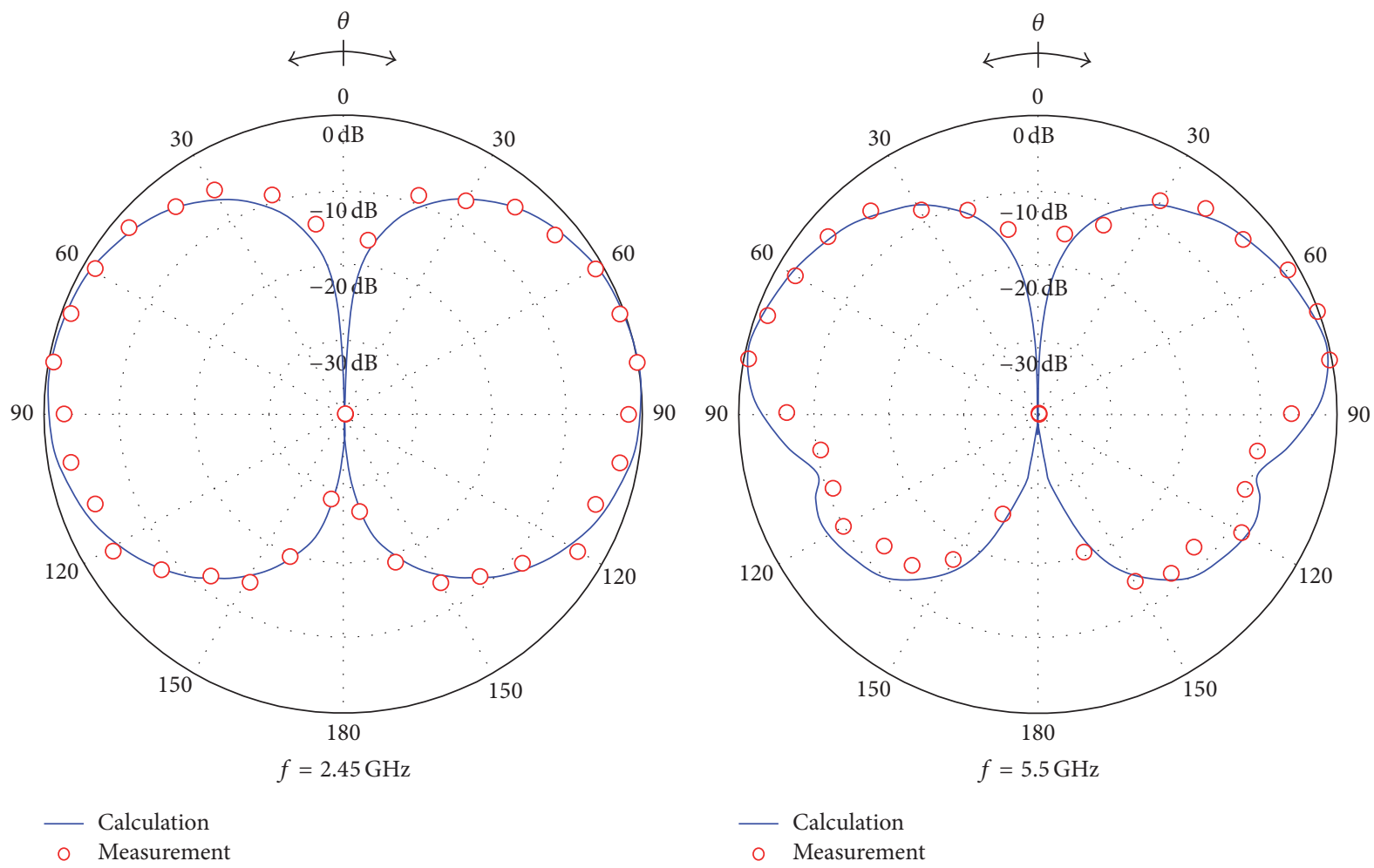

FIGURE 15: Radiation patterns in $y$ - $z$ plane (E-plane).
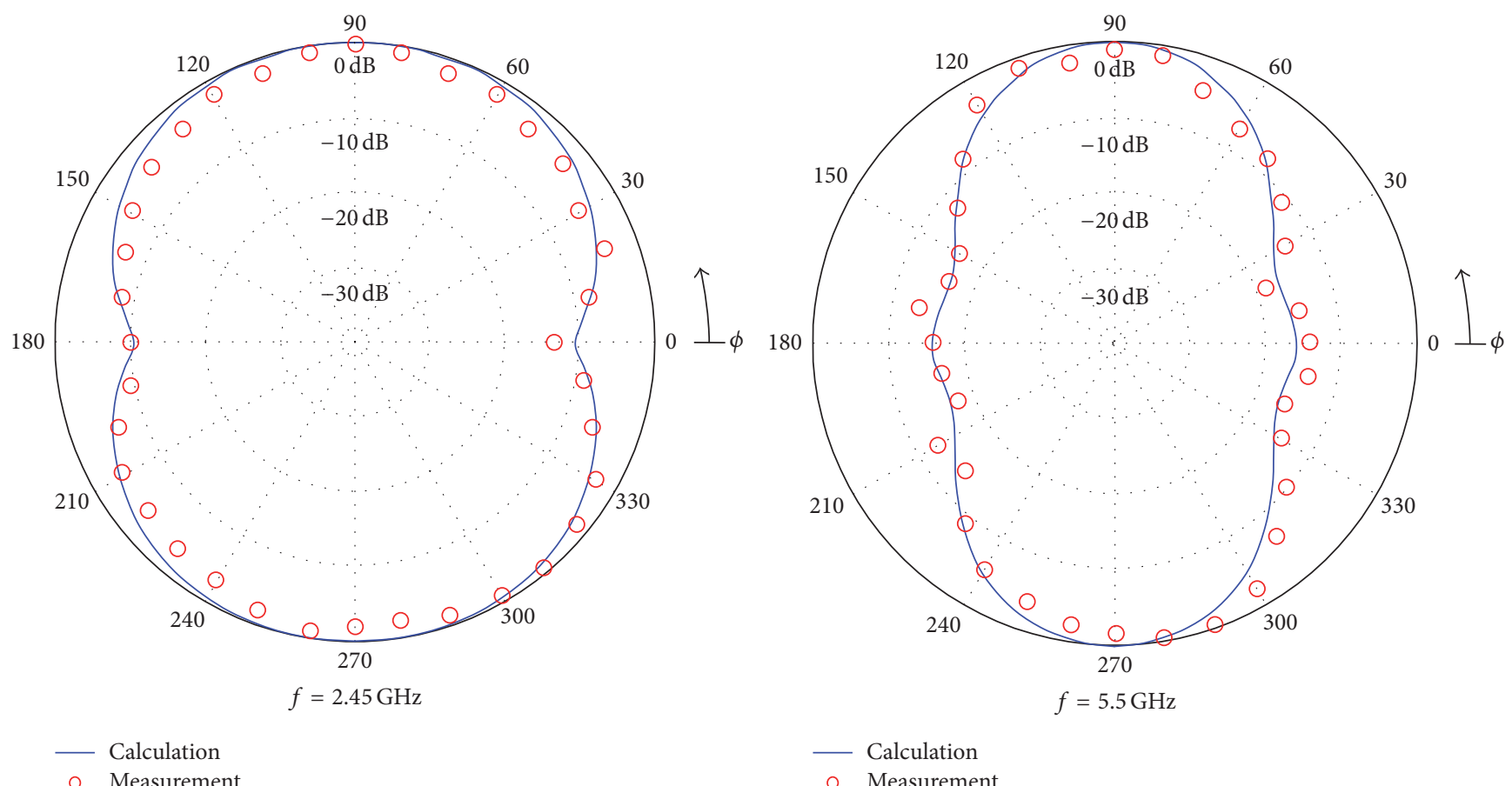

Calculation

o Measurement

○ Measurement

FIgURE 16: Radiation patterns in $x-y$ plane (H-plane). 
TABLE 3: Comparison of some bidirectional antennas used in the $2.4 \mathrm{GHz}$ and/or $5 \mathrm{GHz}$ WLAN bands.

\begin{tabular}{|c|c|c|c|c|c|c|c|c|c|}
\hline \multirow[t]{2}{*}{ Number } & \multirow[t]{2}{*}{ Ref. model } & \multirow{2}{*}{$\begin{array}{l}\text { Freq. band } \\
\text { type }\end{array}$} & \multicolumn{2}{|c|}{$\begin{array}{l}\text { Absolute bandwidth \& } \\
\text { frequency range }(\mathrm{GHz})\end{array}$} & \multicolumn{4}{|c|}{$\begin{array}{l}\text { Peak gain }(\mathrm{dBi}) \\
\text { at specific frequency }\end{array}$} & \multirow{2}{*}{$\begin{array}{c}\text { Overall size } \\
(W \times L \times H) \text { in } \\
\mathrm{mm}\end{array}$} \\
\hline & & & $2.4 \mathrm{GHz}$-band & $5 \mathrm{GHz}$-band & $2.45 \mathrm{GHz}$ & $5.2 \mathrm{GHz}$ & $5.5 \mathrm{GHz}$ & $5.8 \mathrm{GHz}$ & \\
\hline 1 & {$[31]$} & Single & $0.23(2.29-2.52)$ & N/A & 3.8 & N/A & N/A & N/A & $77 \times 142 \times 77$ \\
\hline 2 & {$[32]$} & Single & $0.32(2.32-2.64)$ & N/A & 9.6 & $\mathrm{~N} / \mathrm{A}$ & $\mathrm{N} / \mathrm{A}$ & N/A & $50 \times 160 \times 50$ \\
\hline 3 & {$[33]$} & Dual & $0.28(2.25-2.53)$ & $0.51(5.47-5.98)$ & 5.75 & N/A & 7.00 & 8.50 & $200 \times 200 \times 65$ \\
\hline 4 & [34] & Dual & $0.42(2.22-2.64)$ & $1.16(5.25-6.41)$ & 5.95 & N/A & 6.90 & 8.80 & $200 \times 200 \times 80$ \\
\hline 5 & Proposed & Dual & $0.81(2.10-2.91)$ & $2.39(3.57-5.96)$ & 4.67 & 7.10 & 7.83 & 7.85 & $66 \times 23 \times 67$ \\
\hline
\end{tabular}

fabricated by forming a thin copper sheet, which has the advantages of simple and low-cost structure.

The measured impedance bandwidth of $810 \mathrm{MHz}(2.10-$ $2.91 \mathrm{GHz})$ and $2.39 \mathrm{GHz}(3.57-5.96 \mathrm{GHz})$ is achieved for the first and second band, respectively. The matching characteristics on $\left|S_{11}\right|$ curves are $-27.39 \mathrm{~dB}$ and $-25.44 \mathrm{~dB}$ at the center frequency of the first band, $2.45 \mathrm{GHz}$, and the second band, $5.5 \mathrm{GHz}$, respectively. The peak gains are also found applicable, $4.67 \mathrm{dBi}$ at $2.45 \mathrm{GHz}$ and $7.83 \mathrm{dBi}$ at $5.5 \mathrm{GHz}$ for WLAN applications, with bidirectional radiation patterns for both bands. In addition, the radiation patterns of both operating bands are slightly shifted upward near the same $15^{\circ}$ tilt-angle with respect to the horizontal plane, which is suitable for ceiling- and wall-mounted installations.

From the experimental field tests, the proposed antenna was found useful for most applications in long and narrow communication sites in 2.4 and $5 \mathrm{GHz}$ bands as desired. The measured and calculated results were found in good agreement with some discrepancies which arose from the fabrication errors such as the SMA connector and surface probe joining.

\section{Competing Interests}

The authors declare that there is no conflict of interests regarding the publication of this paper.

\section{References}

[1] H. Liu, R. Li, Y. Pan, X. Quan, L. Yang, and L. Zheng, "A multi-broadband planar antenna for GSM/UMTS/LTE and WLAN/WiMAX handsets," IEEE Transactions on Antennas and Propagation, vol. 62, no. 5, pp. 2856-2860, 2014.

[2] R. L. Li, X. L. Quan, Y. H. Cui, and M. M. Tentzeris, "Directional triple-band planar antenna for WLAN/WiMax access points," Electronics Letters, vol. 48, no. 6, pp. 305-306, 2012.

[3] S.-L. Ma and J.-S. Row, "Design of single-feed dual-frequency patch antenna for GPS and WLAN applications," IEEE Transactions on Antennas and Propagation, vol. 59, no. 9, pp. 3433-3436, 2011.

[4] J.-H. Lu and B.-J. Huang, "Planar compact slot antenna with multi-band operation for IEEE $802.16 \mathrm{~m}$ application," IEEE Transactions on Antennas and Propagation, vol. 61, no. 3, pp. 1411-1414, 2013.

[5] C.-T. Lee and K.-L. Wong, "Uniplanar printed coupled-fed PIFA with a band-notching slit for WLAN/WiMAX operation in the laptop computer," IEEE Transactions on Antennas and Propagation, vol. 57, no. 4, pp. 1252-1258, 2009.

[6] P. Rakluea, N. Anantrasirichai, K. Janchitrapongvej, and T. Wakabayashi, "Multiband microstrip-fed right angle slot antenna design for wireless communication systems," ETRI Journal, vol. 31, no. 3, pp. 271-281, 2009.

[7] C.-J. Wang and S.-W. Chang, "Studies on dual-band multi-slot antennas," Progress in Electromagnetics Research, vol. 83, pp. 293-306, 2008.

[8] S. Hong, W. Kim, H. Park, S. Kahng, and J. Choi, "Design of an internal multiresonant monopole antenna for GSM900/ DCS1800/US-PCS/S-DMB operation," IEEE Transactions on Antennas and Propagation, vol. 56, no. 5, pp. 1437-1443, 2008.

[9] L. Han, W. Zhang, G. Han, R. Ma, and L. Li, "Differential dualfrequency antenna for wireless communication," ETRI Journal, vol. 30, no. 6, pp. 877-879, 2008.

[10] J.-Y. Sze, C.-I. G. Hsu, and J.-J. Jiao, "CPW-fed circular slot antenna with slit back-patch for $2.4 / 5 \mathrm{GHz}$ dual-band operation," Electronics Letters, vol. 42, no. 10, pp. 563-564, 2006.

[11] T.-H. Kim and D.-C. Park, "Compact dual-band antenna with double L-slits for WLAN operations," IEEE Antennas and Wireless Propagation Letters, vol. 4, no. 1, pp. 249-252, 2005.

[12] S. Kosulvit, C. Phongcharoenpanich, M. Krairiksh, and T. Wakabayashi, "Radiation characteristics of a bidirectional antenna using a linear probe in a rectangular ring," in Proceedings of the International Conference on Microwave and Millimeter Wave Technology (ICMMT '98), pp. 337-340, Beijing, China, August 1998.

[13] S. Kosulvit, M. Krairiksh, C. Phongcharoenpanich, and T. Wakabayashi, "A simple and cost-effective bidirectional antenna using a probe excited circular ring," IEICE Transactions on Electronics, vol. 84, no. 4, pp. 443-450, 2001.

[14] S. Lamultree, C. Phongcharoenpanich, S. Kosulvit, and M. Krairiksh, "Investigations of a bidirectional antenna using a probe excited rectangular ring," in Proceedings of the Asia-Pacfic Microwave Conference (APMC '05), vol. 5, pp. 2943-2946, 2005.

[15] S. Lamultree, C. Phongcharoenpanich, S. Kosulvit, and M. Krairiksh, "Analysis of radiation characteristics of a probeexcited rectangular ring antenna by the dyadic Green's function approach," Progress in Electromagnetics Research B, vol. 11, pp. 79-101, 2009.

[16] K. Chawanonphithak, C. Phongcharoenpanich, S. Kosulvit, and M. Krairiksh, "Characteristics of an elliptical ring antenna excited by a linear electric probe," International Journal of Electronics, vol. 94, no. 10, pp. 973-984, 2007.

[17] K. Cho, T. Hori, H. Tozawa, and S. Kiya, "Bidirectional rod antennas comprising collinear antenna and parasitic elements," IEICE Transactions on Communications, no. 6, pp. 1255-1260, 1998. 
[18] K. Cho, T. Hori, and K. Kagoshima, "Bidirectional rod antennas comprising a narrow patch and parasitic elements," IEICE Transactions on Communications, vol. 84, no. 9, pp. 2482-2489, 2001.

[19] H. Liu, B.-Z. Wang, and W. Shao, "Dual-band Bi-directional pattern reconfigurable fractal patch antenna for millimeter wave application," International Journal of Infrared and Millimeter Waves, vol. 28, no. 1, pp. 25-31, 2007.

[20] C. Delgado, E. Garcia, J. Moreno, I. González, and F. Catedra, "An overview of the evolution of method of moments techniques in modern EM simulators," Progress in Electromagnetics Research, vol. 150, pp. 109-121, 2015.

[21] S. M. Rao, D. R. Wilton, and A. W. Glisson, "Electromagnetic scattering by surfaces of arbitrary shape," IEEE Transactions on Antennas and Propagation, vol. 30, no. 3, pp. 409-418, 1982.

[22] B. M. Kolundzija and B. D. Popovic, "Entire-domain Galerkin method for analysis of metallic antennas and scatterers," IEE Proceedings H-Microwaves, Antennas and Propagation, vol. 140, pp. 1-10, 1993.

[23] S.-O. Park, C. A. Balanis, and C. R. Birtcher, "Analytical evaluation of the asymptotic impedance matrix of a grounded dielectric slab with roof-top functions," IEEE Transactions on Antennas and Propagation, vol. 46, no. 2, pp. 251-259, 1998.

[24] I. Hänninen, M. Taskinen, and J. Sarvas, "Singularity subtraction integral formulae for surface integral equations with RWG, rooftop and hybrid basis functions," Progress in Electromagnetics Research, vol. 63, pp. 243-278, 2006.

[25] Y. Liu and K. J. Webb, "On detection of the interior resonance errors of surface integral boundary conditions for electromagnetic scattering problems," IEEE Transactions on Antennas and Propagation, vol. 49, no. 6, pp. 939-943, 2001.

[26] R. A. Shore and A. D. Yaghjian, "Dual-surface integral equations in electromagnetic scattering," IEEE Transactions on Antennas and Propagation, vol. 53, no. 5, pp. 1706-1709, 2005.

[27] K. F. A. Hussein, "Fast computational algorithm for EFIE applied to arbitrarily-shaped conducting surfaces," Progress in Electromagnetics Research, vol. 68, pp. 339-357, 2007.

[28] S. Hatamzadeh-Varmazyar, M. Naser-Moghadasi, and Z. Masouri, "A moment method simulation of electromagnetic scattering from conducting bodies," Progress in Electromagnetics Research, vol. 81, pp. 99-119, 2008.

[29] J. Yuan, C. Gu, and G. Han, "A hybrid equivalent dipole moment and adaptive modified characteristic basis function method for electromagnetic scattering by multilayered dielectric bodies," International Journal of RF and Microwave Computer-Aided Engineering, vol. 19, no. 6, pp. 685-691, 2009.

[30] E. Khoomwong, A. Innok, and C. Phongcharoenpanich, "Bidirectional ring antenna fed by a superellipse surface probe for $2.4 / 5 \mathrm{GHz}$ WLAN applications," in Proceedings of the 13th International Conference on Electrical Engineering/Electronics, Computer, Telecommunications and Information Technology (ECTI-CON '16), 4 pages, Chiangmai, Thailand, June 2016.

[31] Y. Zhao, Z. Zhang, K. Wei, and Z. Feng, "A dual circularly polarized waveguide antenna with bidirectional radiations of the same sense," IEEE Transactions on Antennas and Propagation, vol. 62, no. 1, pp. 480-484, 2014.

[32] T. Jia and X. Li, "A compact stacked bidirectional antenna for dual-polarized WLAN applications," Progress in Electromagnetics Research C, vol. 44, pp. 95-108, 2013.

[33] X. Li, L. Yang, S.-X. Gong, and Y.-J. Yang, "Bidirectional high gain antenna for WLAN applications," Progress in Electromagnetics Research Letters, vol. 6, pp. 99-106, 2009.
[34] J. Zhang, X.-M. Zhang, J.-S. Liu, Q.-F. Wu, T. Ying, and H. Jin, "Dual-band bidirectional high gain antenna for WLAN 2.4/5.8 GHz applications," Electronics Letters, vol. 45, no. 1, pp. 6-7, 2009. 


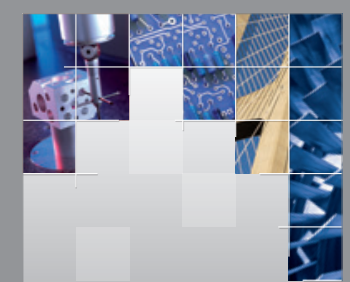

\section{Enfincering}
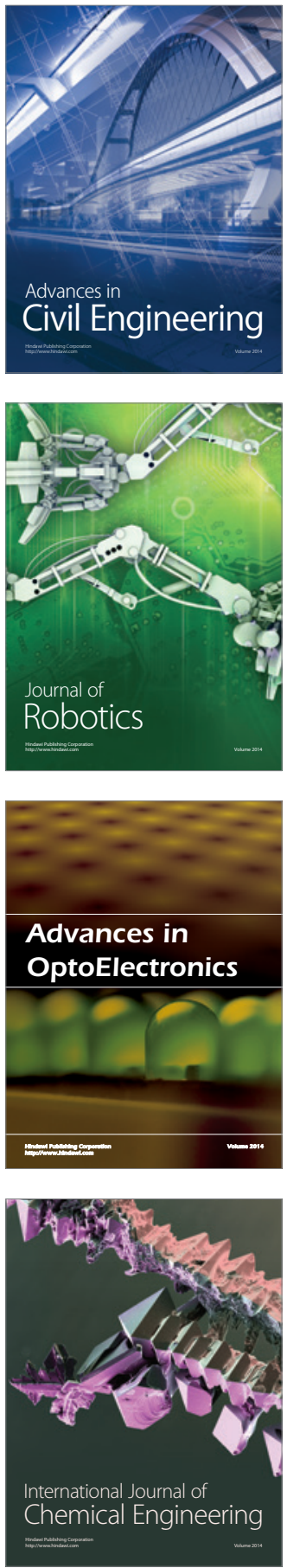

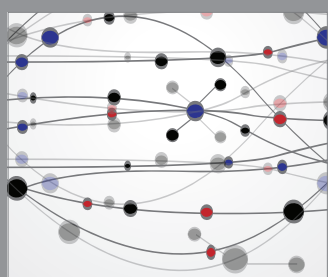

The Scientific World Journal

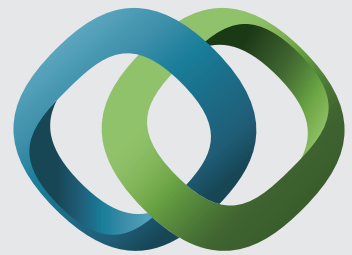

\section{Hindawi}

Submit your manuscripts at

http://www.hindawi.com
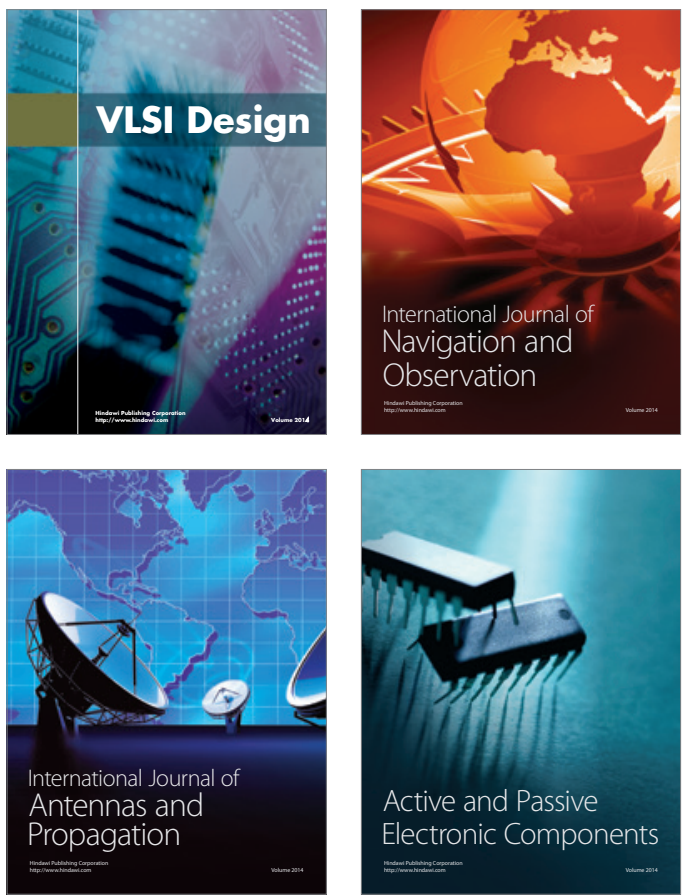
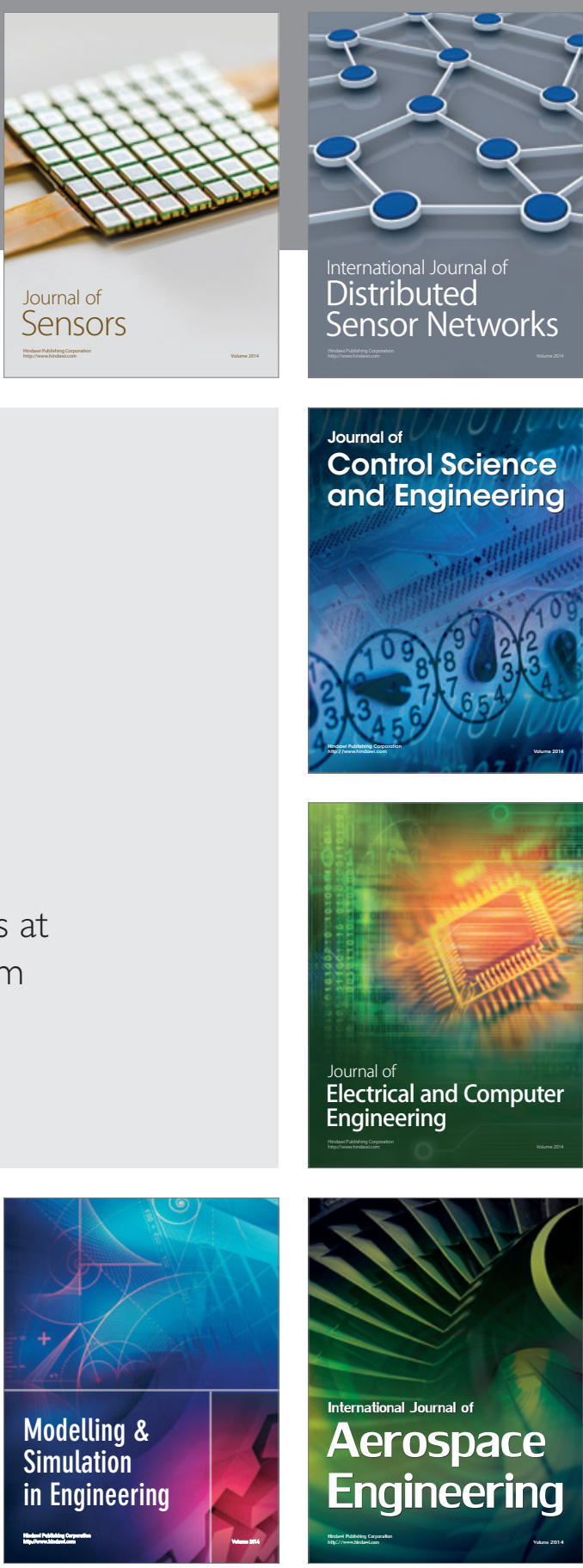

International Journal of

Distributed

Sensor Networks

Journal of

Control Science

and Engineering
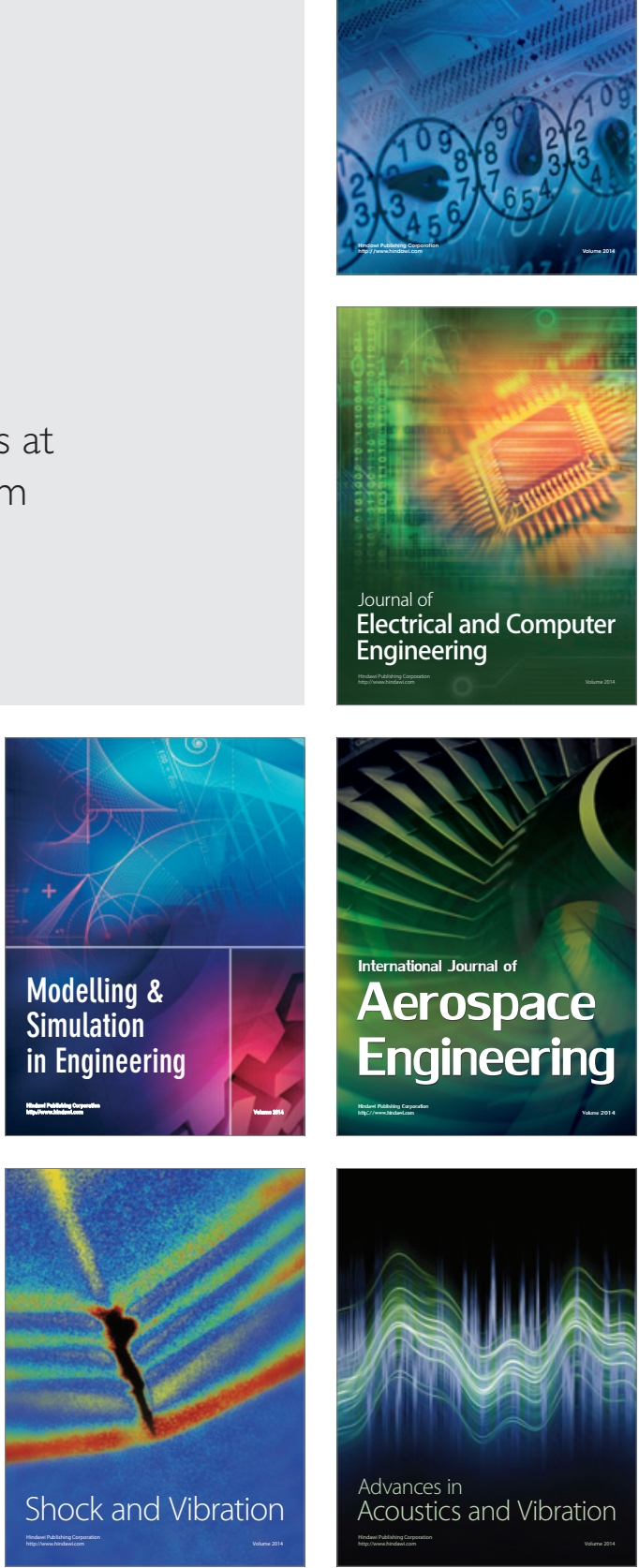